\section{Domiciliary visits}

Sir: We write to highlight the importance of including a home visit in the assessment of a child or adolescent. Although it is commonplace to interview the whole of the family usually in the clinic, a home visit is not routinely carried out by all departments.

We report the case of a 12-year-old Caucasian girl referred to the department of Child and Adolescent Psychiatry by an Educational Social Worker who was concerned about the girl's poor school attendance. At her first appointment, the patient revealed that she was fearful of contamination by germs and had several rituals involving the preparation of food. She did not eat with the rest of her family, instead preparing pre-packed frozen meals using her own set of cooking utensils. She insisted on using her own soap and towel before and after meals. She was noted to be pre-pubescent and underweight.

An initial diagnosis of obsessive-compulsive disorder was made and behavioural therapy was recommended. However, subsequent poor attendance at out-patient appointments and complaints by neighbours to Social Services regarding the number of cats owned by the family prompted our home visit.

On visiting the home the reason for the cleaning rituals soon became clear. The family lived in a sparsely furnished flat which was in disrepair. There was no lock on the front door and the house was noted to smell of stale cat urine. The kitchen caused us the greatest concern since approximately 25 cats and their excrement covered all exposed worksurfaces. Our patient proceeded to demonstrate her cleaning rituals to us and it was immediately apparent that these were an understandable response to the insanitary environment she lived in. The case was referred as a matter of urgency to Social Services.

We recommend that the potential benefits of a domiciliary visit is considered on all new referrals since the information gained can be invaluable.

\section{Susan SHaw}

Institute of Psychiatry, London

SUE STOREY

Department of Child and Adolescent Psychiatry. Royal Free Hospital, London

\section{Paychiatry in Tobago}

Sir: I was interested to read the article about psychiatry in Tobago by Dr Cembrowicz (Psychiatric Bulletin, July 1995, 18, 421-426). I have worked in the psychiatric team responsible for Tobago and offer a few comments.

There are factors additional to those mentioned which contribute to Dr Cembrowicz's finding of only $0.5 \%$ of patients at District Health Centres having 'psychological' problems. Few acutely ill psychiatric patients are seen there due, in part, to the adult clinics being held not on a daily basis but weekly or even less frequently in remote areas. Further, a well developed Community Psychiatric Nursing Service often refers patients directly to the psychiatric clinic. Few chronically ill patients are referred to the Health Centres, but instead are followed up in the Psychiatric Clinic, in recognition of the crowding at the Health Centres as well as the limited availability of psychotropic drugs at the pharmacies of the outlying Health Centres.

Dr Cembrowicz's estimate of 118 patients on depot neuroleptics is based on the assumption that each patient received $25 \mathrm{mg}$ of fluphenazine decanoate (Modecate) or $50 \mathrm{mg}$ of pipothiazine palmitrate (Piportil) monthly. In the psychiatric clinic there, and indeed the ones I have worked in within the UK, it is the exception rather than the rule for young adults to be maintained on this dosage. (The British National Formulary's (1995) dose for Modecate is up to $100 \mathrm{mg}$ every 14 days and Piportil up to $200 \mathrm{mg}$ every 4 weeks). With patients possibly receiving up to eight times the assumed dose, I cannot agree with the author that the number treated with depots "may be reasonably accurate".

While very rough estimates of patient numbers are unavoidable using Dr Cembrowicz's methodology, I think it is wrong to use them to calculate rates per 100000 for patients treated for psychosis and depression as these rates must lack validity. It is unfortunate that they are now liable to be quoted in the literature.

\section{Reference}

Brtish Medical assoclation and the Pharmaceutical SOCIETY (1995) British National Formulary, 29, 161-162.

\section{A. RATAN}

Leicestershire Mental Health Service NHS Trust. Psychiatric Unit,

Gwendolen Road, Leicester LE5 4PW

Sir: My estimates are based on the doses Clinic staff told me they used at the time. Tobagonian treatments will not necessartly correspond with the (maximum) British National Formulary dosages you describe. Perhaps my estimates will stimulate the production of more detailed statistics?

Great credit is due to local community psychiatric nurses who gave a sterling service at a time of great economic difficulty, often with little psychiatric support due to local transport difficulties. 